\title{
A Equipe de Enfermagem de Hospital Escola Público e os Acidentes de Trabalho com Material Biológico
}

\author{
The Nursing Team of a Public Teaching Hospital and the Work \\ Accidents With Biological Material
}

\author{
Iara Aparecida de Oliveira Sêcco ${ }^{1}$; Paulo Roberto Gutierrez²; \\ Tiemi Matsuo ${ }^{3}$; Maria Lúcia do Carmo Cruz Robazzi ${ }^{4}$
}

\begin{abstract}
Resumo
Notificações de acidentes de trabalho (ATs) são instrumentos de vigilância epidemiológica e avaliação da situação de saúde do trabalhador, dos riscos ocupacionais e dos processos de trabalho em que esses estão inseridos, possibilitando implementação de estratégias de promoção à sua saúde. Este estudo objetivou analisar os ATs com material biológico (ATMB) notificados entre trabalhadores de enfermagem de Hospital-Escola Público, no período de 1995 a 2000, estimar indicadores de risco e avaliar o impacto da implantação do Programa de ATMB na Instituição. A coleta de dados deu-se por meio das Comunicações de Acidentes de Trabalho e das Notificações de Acidentes de Trabalho com Material Biológico, documentos estes obtidos nos órgãos competentes da Instituição. Para a tabulação e análise estatística, foi utilizado o Programa Epi-Info e a Planilha Eletrônica Excel. Verificou-se que, dos 421 acidentes notificados, 53,4\% (225) referiram-se a ATMB, com Coeficiente de Risco (CR) médio anual de 5,9 acidentes para cada 100 trabalhadores. Os auxiliares de enfermagem foram acometidos por 90,2\% (203) dos ATMB notificados apresentando o maior CR médio anual, igual a 6,8. A parte do corpo mais atingida foram as mãos, com freqüência de $82,8 \%$ dos casos e CR médio anual de 4,9. As perfurações representaram o total de 70,7\% (159) dos ATMB e mostraram CR médio anual de 4,2, associadas, principalmente, às tarefas de punções venosas. Em 11,6\% (26) dos ATMB, houve exposição ocupacional a pacientes soropositivos para HIV. Verificou-se a necessidade de manutenção de ações de educação para os profissionais de enfermagem, bem como revisão dos processos de trabalho a que esses estão expostos, promovendo a prevenção de doenças ocupacionais graves como a AIDS e Hepatite B. Também, se observou a necessidade de orientação à equipe quanto à legislação vigente, para melhorar o fluxo das notificações para a maior segurança do trabalhador e conferindo-lhe o amparo legal necessário.
\end{abstract}

Palavras-Chave: Acidentes de trabalho. Riscos biológicos. Hospitais. Enfermagem.

\footnotetext{
${ }^{1}$ Docente de Enfermagem da Universidade Norte do Paraná, Mestre em Saúde Coletiva, Doutoranda da Escola de Enfermagem de Ribeirão Preto-Universidade de São Paulo e Enfermeira da Assessoria Técnica de Enfermagem do Hospital Universitário Regional do Norte do Paraná. E-mail: iarasecco@uel.br

${ }^{2}$ Docente do Departamento de Saúde Coletiva do Centro de Ciências da Saúde da Universidade Estadual de Londrina, Doutor em Ciências da Saúde.

${ }^{3}$ Docente do Departamento de Matemática Aplicada do Centro de Ciências Exatas da Universidade Estadual de Londrina, Doutora em Estatística.

${ }^{4}$ Docente Titular da Escola de Enfermagem de Ribeirão Preto - Universidade de São Paulo, Doutora em Enfermagem.
} 


\begin{abstract}
Notifications of work accidents are instruments of epidemiological surveillance and evaluation of worker's health conditions, occupational risks and work processes with which the worker is involved, enabling the implementation of strategies for health promotion. The purpose of this study was to analyze the work accidents with biological material that took place with nursing professionals in a Public Teaching Hospital, in the period from 1995 through 2000, to estimate risk indicators and to evaluate the impact of the implementations of the program of Work Accidents with Biological Materials (WABM) in the Institution. The data collection was made through the Report of Work Accidents and Notification of Work Accidents with Biological Material obtained from the competent divisions in the Institution. The statistical analysis used the Program Epi-Info and the Excel Electronic Plan. It was verified that out of the 421 reported accidents, 53,4\% (225) referred to work accidents with biological material, with annual average risk coefficient of 5,9 per worker. The nursing assistants accounted for 90,2\% (203) of the work accidents with biological material, with the highest annual average risk coefficient, that is 6,8 . The mostly affected body parts were the hands, with a frequency of $82,8 \%$ of the cases and annual average risk coefficient of 4,9. The perforations represented a total of 70,7\% (159) of the work accidents with biological material and 4,2 of annual average coefficient, associated mainly with the work of venous punches. In $11,6 \%$ of the work accidents with biological material there was occupational exposure to HIV serum positive patients. It was also verified the need to maintain educational actions for nursing professionals as well as of a review of the work processes to which these professionals are exposed, promoting the prevention of serious occupational diseases such the AIDS and Hepatitis B. There is also the need to guide the team as to the current legislation in order to improve the flow of notification for a better safety of the worker while providing him with the necessary legal support.
\end{abstract}

Key words: Work accidents. Biological risks. Hospitals. Nursing.

\section{Introdução}

O Ministério da Saúde (MS), atualmente, conceitua os hospitais como "parte integrante de uma organização médica e social, cuja função básica consiste em proporcionar à população assistência médica integral, curativa e preventiva, sob quaisquer regimes de atendimento, inclusive domiciliar, constituindo-se também em centro de educação, capacitação de recursos humanos e de pesquisa em saúde, bem como os encaminhamentos de pacientes, cabendo-lhes supervisionar e orientar os estabelecimentos de saúde a ele vinculados tecnicamente" (BRASIL, 2002).

Notadamente, hospitais, especialmente os públicos, têm sido espaço de expressiva expansão administrativa, tecnológica e científica, de modo que eles devem adequar-se, constantemente, às peculiaridades dos clientes, às necessidades do ensino, da pesquisa e das políticas públicas de atenção à saúde.

É importante considerar que o ambiente hospitalar mostra-se reconhecidamente insalubre por agrupar portadores de diversas enfermidades infecciosas, além de viabilizar procedimentos que oferecem riscos profissionais diversos para os trabalhadores que atuam nestas Instituições (BULHÕES, 1994; PRADO et al., 1999). Há que se lembrar, ainda, do caráter industrial destas Instituições, como o caso dos serviços que envolvem centrais de processamento e esterilização de materiais, cozinha, manutenção de equipamentos, zeladoria, laboratórios, lavanderia, entre outros (OLIVEIRA; MAKARON; MORRONE, 1982)

Os trabalhadores que atuam nestas unidades estão expostos a muitos riscos ocupacionais que culminam com a ocorrência de acidentes de trabalho de natureza variada. Os Acidentes de Trabalho (ATs) apresentam-se como a concretização dos agravos à saúde dos trabalhadores em decorrência da atividade produtiva, ao receberem interferências do que diz respeito à aspectos inerentes à própria pessoa, do ponto de vista físico ou psíquico, bem como do contexto social, econômico, político e da própria existência (BARBOSA, 1989; SILVA, 1996). 
Decorrem da ruptura na relação entre o trabalhador e as condições e/ou ambiente de trabalho, que interferem no seu processo saúde-doença (MENDES, 1995).

Segundo a Lei $n^{\circ} .8 .213$, de 24 de julho de 1991 (BRASIL, 1992a), alterada pelo Decreto $\mathrm{n}^{\circ} .611$, de 21 de julho de 1992 (BRASIL, 1992b), no artigo $19^{\circ}$." "acidente do trabalho é aquele que ocorre pelo exercício do trabalho, a serviço da empresa ou ainda, pelo serviço de trabalho de segurados especiais, provocando lesão corporal ou perturbação funcional que cause a morte, a perda ou redução da capacidade para o trabalho, permanente ou temporária. São considerados, também, como AT os acidentes de trajeto, as doenças profissionais e as doenças do trabalho.

Os profissionais da equipe de enfermagem inseridos na dinâmica da assistência hospitalar estão particularmente expostos à ocorrência de ATs, resultantes dos processos de trabalho desenvolvidos e, por conseguinte, dos processos de produção de serviços que envolvem a promoção e preservação da saúde dos usuários dos serviços de saúde. Salienta-se, entre os agravantes que predispõem a essas ocorrências, a proximidade física necessária na prestação da assistência, que possibilitam a ocorrência dos AT envolvendo a exposição a materiais biológicos potencialmente contaminados.

Conceitualmente, acidentes de trabalho com material biológico (ATMB) são os decorrentes do contato com materiais biológicos humanos (sangue, secreções e excreções), provocados pelo manuseio de objetos perfurocortantes (agulhas, bisturis, etc) e por respingos em mucosas; são acidentes do trabalho tipo, podendo levar à doença profissional aguda, crônica ou até mesmo à morte (HOEFEL; SCHNEIDER, 1997).

Entre os possíveis agravos à saúde dos trabalhadores de enfermagem estão a Síndrome da Imunodeficiência Adquirida (AIDS) e a Hepatite B e C. O risco de transmissão do HIV para os trabalhadores da área da saúde, em consequiência da exposição aos acidentes com agulhas, tem sido estimado em $0,3 \%$ em vários estudos, enquanto a probabilidade de infecção pelo vírus da hepatite $\mathrm{B}$ pode atingir até $40 \%$ em situações em que o paciente fonte de contaminação apresente sorologia positiva ao antígeno da hepatite $\mathrm{B}$. $\mathrm{O}$ risco da hepatite $\mathrm{C}$ é de $1,8 \%$, ou, de $1 \%$ a $10 \%$. Já a exposição a mucosas íntegras ao fluido contaminado traz o risco médio de $0,1 \%$ e a exposição de pele íntegra apresenta um risco menor de 0,1\% (CARDO; BELL, 1997; BRASIL, 1999).

Mais de 20 diferentes tipos de patologias podem ser veiculadas em decorrência de exposições aos materiais perfurocortantes contaminados com sangue, e, assim, as exposições ocupacionais a esses patógenos devem ser tratadas como emergência médica pela necessidade de intervenções rápidas para assegurar a maior eficácia possível das medidas (BRASIL, 1999).

Contudo, o MS ressalta que essas medidas profiláticas após a exposição não são totalmente eficazes, e enfatiza a necessidade de medidas preventivas permanentes pela adoção das Precauções Universais (PU), para a redução do risco de infecção pelo HIV ou hepatite em ambiente ocupacional (CARDO; BELL, 1997; BRASIL, 1999).

Os Centers for Disease Control and Prevention - CDC - de Atlanta (Estados Unidos da América) confirmaram 56 (cinqüenta e seis) casos de trabalhadores da assistência médica nos EUA que apresentaram soroconversão para o vírus da AIDS, depois de se haverem expostos acidentalmente a ele no trabalho. Entre esses casos, 85\% (48) deram-se por contato percutâneo, por exemplo, por punções e cortes, $9 \%$ (5) por contatos com membrana mucosa ou pele, $4 \%$ (2) por exposição a contato mucocutâneo e percutâneo simultaneamente e $2 \%$ (1) de forma desconhecida (CENTERS FOR DISEASE CONTROL AND PREVENTION, 2001).

Quanto à hepatite $\mathrm{B}$, os CDC deram a conhecer que, nos Estados Unidos, são diagnosticados anualmente aproximadamente 800 casos de 
contaminação decorrente de exposição ocupacional, embora os números já tenham decrescido em conseqüência da imunização dos profissionais mediante a vacina da hepatite B (CENTERS FOR DISEASE CONTROL AND PREVENTION, 1999). No Brasil, estes dados não estão disponíveis no MS.

Já com relação à hepatite $\mathrm{C}$, os referidos Centros apresentaram o fato de não haver estimativas exatas do número de profissionais infectados; contudo, informaram que há estudos apresentando o valor de $1 \%$ de profissionais de saúde infectados pelo vírus da hepatite $\mathrm{C}$, embora não se tenha conhecimento do número daqueles atingidos pós exposição ocupacional (CENTERS FOR DISEASE CONTROL AND PREVENTION, 1999).

É considerável a necessidade de buscar alternativas que preservem os profissionais de saúde dos riscos decorrentes dessas exposições. As denominadas medidas de biossegurança prestam-se a essa finalidade e foram definidas por Rodrigues, Magalhães e Sales (1995) como: "o conjunto de medidas empregadas pelo indivíduo, no seu processo de trabalho, que permite a sua autoproteção e a manutenção de sua condição de saúde, ao mesmo tempo que estabelece condições seguras e protetoras para o paciente".

Muitos autores têm realizado estudos abordando os ATMB atingindo pessoal de enfermagem nas instituições hospitalares, principalmente aqueles causados por instrumentos perfurocortantes.

Gir, Costa e Silva (1998) lembram que, antes do conhecimento do HIV, acidentes de perfuração causados por agulhas eram subestimados, embora já fosse conhecido que muitos patógenos poderiam ser transmitidos por meio de sangue contaminado, o que também poderia acarretar agravos importantes à saúde dos trabalhadores.

Outra agravante, especialmente nos ambientes cirúrgicos, é a possibilidade da ocorrência de lesões por perfuração por agulhas sem que os envolvidos se dêem conta, conforme aponta Marchese et al. (2000).
Santos et al. (1989), Machado et al. (1992), Gir, Costa e Silva (1998), Kuchenbecker (1999), Brandi, Benatti e Alexandre (1998), demonstraram, em seus estudos, a gravidade da exposição aos instrumentos perfurocortantes de uso profissional pelos trabalhadores de enfermagem, bem como a importância das atividades de educação continuada, prevenção sistemática dos riscos profissionais, com a conseqüente diminuição da qualidade de vida.

Em todos os estudos são recomendados programas de educação continuada para o uso das Precauções Padrão (PP) como estratégia fundamental para a diminuição dos casos de exposição ocupacional aos materiais biológicos, especialmente no manuseio de agulhas e outros materiais perfurantes. Enfatiza-se não só a necessidade de os profissionais estarem informados sobre a atual dimensão da AIDS, devido à grande quantidade de indivíduos infectados e assintomáticos e às diferentes formas de contágio, mas também a necessidade de obediência irrestrita às normas de proteção individual durante a atividade profissional (CARDO; BELL, 1997; MACHADO et al., 1992; RODRIGUES, MAGALHÃES; SALES, 1995; GIR, COSTA; SILVA, 1998; SOUZA, 1999; SARQUIS, 1999).

Lembra Sarquis (1999) que a grande maioria dos ATs que atinge os profissionais de enfermagem e compromete a sua saúde, está relacionada ao instrumento de trabalho utilizado no desempenho da função, ao ritmo do trabalho empreendido na jornada, e às contingências pessoais da vida particular destes trabalhadores. Esses fatores contribuem para a ocorrência desses acidentes.

Em síntese, é relevante o problema dos AT que envolvem a equipe de enfermagem, em especial os ATMB. Entretanto, na busca de estratégias que previnam os trabalhadores desses infortúnios, há que se atentar para os processos de trabalho envolvidos no desenvolvimento dessas atividades e nas relações sociais em que estes se dão.

Ademais, "todo grupo social tem direito a condições de vida compatíveis com sua sobrevivência 
e com o desenvolvimento de suas potencialidades e projetos. Esta é uma exigência ética permanente para a epidemiologia e para a planificação das ações de saúde e bem-estar" (CASTELLANOS, 1999).

\section{Objetivos}

Este estudo descritivo objetivou: a) analisar os acidentes de trabalho com material biológico (ATMB) notificados entre trabalhadores de enfermagem de Hospital Escola Público do Norte do Paraná (HU), no período de 1995 a 2000, segundo as variáveis ligadas à pessoa, tempo e espaço; b) caracterizar esses acidentes em relação aos AT de outra natureza ocorridos no mesmo período do estudo; c) estimar indicadores de risco para as variáveis estudadas; d) estudar relações entre as cargas de trabalho presentes nos processos de trabalho e a ocorrência dos acidentes; e) avaliar o impacto das estratégias educativas desenvolvidas na Instituição e a implantação do Programa de ATMB ocorridos no segundo triênio do estudo.

\section{Material e Métodos}

Após aprovação do projeto no Comitê de Bioética da Instituição (Anexo 1) foi realizada a pesquisa, sob o referencial teórico da epidemiologia descritiva.

O HU é Órgão Suplementar de uma Universidade Estadual do Paraná. Trata-se do único hospital público de grande porte no Norte do Estado, e é considerado o terceiro maior hospital-escola em todo o Sul do Brasil. Constitui-se Centro de Referência Regional para o Sistema Único de Saúde (SUS) em praticamente todas as especialidades médicas, com capacidade de internações para 333 leitos (UNIVERSIDADE ESTADUAL DE LONDRINA, 2000).

A população do estudo foi composta pelos trabalhadores da equipe de enfermagem do $\mathrm{HU}$ atuante na Instituição no período de 1995 a 2000, num total médio anual de 631,3 trabalhadores. Desse total, a média anual foi de 15,0\% $(94,5)$ de enfermeiros, $0,8 \%$ (5) de técnicos de enfermagem,
$78,0 \%(492,3)$ de auxiliares de enfermagem e 6,3\% $(39,5)$ de atendentes de enfermagem.

O número de 5 técnicos de enfermagem foi adicionado ao total dos auxiliares de enfermagem.

A coleta de dados foi realizada por meio das Comunicações de Acidentes de Trabalho do ano de 1995 a 2000, Notificações de Acidentes de Trabalho com Material Biológico (NATMB) de 1998 a 2000, documentos obtidos no Serviço Especializado em Segurança e Medicina do Trabalho, Unidade de Pronto Socorro e na Regional de Saúde.

Salienta-se que as NATMB são decorrentes da implantação do Programa de Acidentes de Trabalho com Material Biológico (PATMB) no Hospital, em 1998, programa este viabilizado em todo o Estado do Paraná por iniciativa da Secretaria de Estado da Saúde, atendendo à normatização do MS, que, por sua vez, seguiu as recomendações dos CDC dos EUA (BRASIL, 1999; PARANÁ, 1998). O referido Programa contou com a participação de todos os órgãos educativos envolvidos na Instituição como a Comissão Controle de Infecção Hospitalar, Comissão Interna de Prevenção de Acidentes, Departamento de Educação e Treinamento da Diretoria de Enfermagem, entre outros.

Foi construído um banco de dados através do Programa Epi-Info. Para a tabulação e análise estatística foi utilizado o Programa Epi-Info e a Planilha Eletrônica Excel.

Foram calculados os Coeficientes de Risco (LAURENTI, 1987), a partir dos dados referentes ao número de servidores ano a ano (UNIVERSIDADE ESTADUAL DE LONDRINA, 2001).

\section{Resultados}

Verificou-se resultados expressivamente oscilantes de um período a outro, o que reforça a necessidade de estabelecer estratégias vigilância epidemiológica constante para estes eventos. Este desfecho está baseado nos resultados apresentados a seguir. 


\section{Caracterização dos ATMB em relação aos AT de outra natureza}

Tabela 1 - Distribuição anual dos trabalhadores da equipe de enfermagem do HURNP, notificações de ATMB, e de AT de outra natureza, CR respectivos e RR. Londrina, 1995 a 2000.

\begin{tabular}{|c|c|c|c|c|c|c|c|c|}
\hline \multirow{2}{*}{$\begin{array}{c}\text { ANO DO } \\
\text { ACIDENTE }\end{array}$} & \multirow{2}{*}{$\begin{array}{c}\text { * NÚMERO DE } \\
\text { TRABALHADORES }\end{array}$} & \multicolumn{3}{|c|}{$A T M B$} & \multicolumn{3}{|c|}{ AT DE OUTRA NATUREZA } & \multirow{2}{*}{$\begin{array}{c}R R \\
(R A Z \tilde{A} O \\
C R 1 / C R 2)\end{array}$} \\
\hline & & $\mathrm{n} 1$ & $\%$ & C R 1 & $\mathrm{n} 2$ & $\%$ & C R 2 & \\
\hline 1995 & 628 & 21 & 9,3 & 3,3 & 40 & 20,4 & 6,4 & 0,5 \\
\hline 1996 & 636 & 30 & 13,3 & 4,7 & 34 & 17,4 & 5,3 & 0,9 \\
\hline 1997 & 641 & 22 & 9,8 & 3,4 & 34 & 17,4 & 5,3 & 0,7 \\
\hline 1998 & 638 & 60 & 26,7 & 9,4 & 32 & 16,3 & 5,0 & 1,9 \\
\hline 1999 & 603 & 39 & 17,3 & 6,5 & 21 & 10,7 & 3,5 & 1,9 \\
\hline 2000 & 642 & 53 & 23,6 & 8,3 & 35 & 17,9 & 5,5 & 1,5 \\
\hline TOTAL & & 225 & 100,0 & & 196 & 100,0 & & \\
\hline $\begin{array}{l}\text { MÉDIA } \\
\text { ANUAL }\end{array}$ & 631,3 & 37,5 & & 5,9 & 32,7 & & 5,2 & 1,2 \\
\hline
\end{tabular}

Fonte: Universidade Estadual de Londrina (2001).

Foram notificados oficialmente, por meio das CAT e das NATMB, 225 ATMB na equipe de enfermagem do Hospital, no período de 1995 a 2000. Esse total refere-se a $53,4 \%$ do total dos 421 ocorridos no mesmo período do estudo e que foram destacados como objeto central da pesquisa.

O grande contingente de trabalhadores de enfermagem acidentados com exposição a material biológico em hospitais também foi relatado por vários autores como: Rowe e Giuffre (1991), Mccormick et al. (1991), Machado et al. (1992), Prado et al. (1999), Caetano, Loja e Lima (2000), Kuchenbecker (1999), Pungpapong et al. (1999), Chaves et al. (2000), entre outros.

No Hospital em estudo, Sêcco e Gutierrez (2001a, 2001b), verificaram que, dos 1387 acidentes notificados que ocorreram em toda a Universidade, $30,43 \%$ (422) deram-se por exposição a materiais biológicos. Da mesma maneira, no Hospital, Órgão Suplementar da mesma Universidade, observou-se que, dos 791 acidentes ocorridos na Instituição, 36,92\% (292) também foram ocorrências dessa natureza.

O presente estudo levantou o $\mathrm{CR}$ anual dos ATMB e AT de outra natureza notificados na equipe de enfermagem no período do estudo. Na análise do CR médio anual dos ATMB, verificou-se que este foi de 5,9 acidentes para cada 100 trabalhadores de enfermagem, estando os valores entre 3,3 em 1995 e 9,4 em 1998. Observou-se nítida diferença entre os CR referentes aos anos do primeiro triênio (1995 a 1997), com relação aos do segundo (1998 a 2000).

Com respeito ao ano anterior, a avaliação do CR dos ATMB revela um aumento expressivo do indicador referente ao ano de 1998 em relação a 1997, com variação de $174,0 \%$. Esse dado indica a possibilidade de ter ocorrido um impacto positivo nos processos de notificação dos casos decorrentes das medidas educativas implementadas na Instituição e do PATMB. 
A análise dos resultados apresentados na Tabela 1 também evidencia que o RR anual dos ATMB em relação aos AT de outra natureza mostrou números aumentados naqueles do segundo triênio. Enquanto em 1995 o valor foi de 0,5 , em 1998 e 1999, este foi de 1,9, ou seja, um valor próximo ao dobro do número dos outros acidentes notificados, confirmando a importância do problema.

Entre os pesquisadores que levantaram CR de acidentes de AT com perfurocortantes na equipe de enfermagem está Souza (1999), que encontrou o CR de 5,7 acidentes para cada 100 trabalhadores, valor muito próximo ao resultado médio anual encontrado na presente pesquisa. No referido estudo, entretanto, não está quantificado o número exato de acidentes provocados por perfurocortantes contaminados por materiais biológicos. Contudo, pela descrição dos procedimentos, foi possível inferir que a grande maioria estava contaminada por estes elementos.

O Quadro 1 apresenta os CR levantados em outros trabalhos para possibilitar melhor visualização e análise. Apresenta o período compreendido pelo estudo, o CR relativo ao AT com perfurocortantes ou ATMB e o CR levantado para estudo da totalidade dos AT, quando apurado pelo(s) autores).

Quadro 1 - Distribuição de CR de ATMB ou AT por perfurocortantes contaminados, em estudos de AT na equipe de enfermagem.

\begin{tabular}{l|c|c|c|c|c|c|c|c}
\hline $\begin{array}{c}\text { CR / 100 } \\
\text { Trabalhadores }\end{array}$ & $\begin{array}{c}\text { SILVA } \\
(1988)\end{array}$ & $\begin{array}{c}\text { MCCORMICK } \\
\text { et al. (1991) }\end{array}$ & $\begin{array}{c}\text { SILVA } \\
(1996)\end{array}$ & $\begin{array}{c}\text { BENATTI } \\
(1997)\end{array}$ & $\begin{array}{c}\text { BRANDI, } \\
\text { BENATTIE } \\
\text { ALEXANDR } \\
E \text { (1998) }\end{array}$ & $\begin{array}{c}\text { SARQUIS } \\
(1999)\end{array}$ & $\begin{array}{c}\text { SOUZA } \\
(1999)\end{array}$ & $\begin{array}{c}* \text { SECCO } \\
(2001)\end{array}$ \\
\hline $\begin{array}{l}\text { Tempo de referência } \\
\text { do Indicador }\end{array}$ & 4 anos & Anual & Anual & Semestral & 7 meses & Anual & Anual & Anual \\
\hline $\begin{array}{l}\text { ATMB/ } \\
\text { perfurocortantes } \\
\text { contaminados }\end{array}$ & 19,65 & & & 3,8 & 7,6 & 5,7 & 5,9 \\
\hline \begin{tabular}{l} 
Totalidade de AT \\
\hline
\end{tabular} & $* * 12,54$ & & 19,00 & 8,20 & & 13,26 & & 11,1 \\
\hline
\end{tabular}

* Dado do presente estudo; ** CR de afastamento por AT.

Pelos resultados apresentados, é possível verificar que Mccormick et al. (1991), em estudo nos EUA, encontraram valores muito superiores aos encontrados nas pesquisas nacionais. Entretanto, os estudos brasileiros de Brandi, Benatti e Alexandre (1998), Sarquis (1999) e Souza (1999), ressalvadas as diferenças metodológicas, mostraram valores semelhantes aos achados desta pesquisa.

$\mathrm{Na}$ análise estatística da relação entre o número de ATMB e de AT de outra natureza notificados nos dois triênios deste estudo, os resultados mostraram que o aumento proporcional de ATMB no segundo triênio foi significativo quando comparado aos resultados dos acidentes de outra natureza (Teste de c2 $=21,03 ; 1$ grau de liberdade; $\mathrm{p}<0,0001$.)
Os achados, possivelmente, decorreram em resposta ao PATMB e às atividades educativas implementadas na Instituição.

O presente trabalho dá a conhecer que, em todos os anos do estudo, os ATMB foram os acidentes que proporcionaram riscos expressivos aos trabalhadores de enfermagem da Instituição, o que evidencia a gravidade do problema. Esses riscos, na visão da autora, são inerentes à atividade profissional, e ocorrem nas diversas atividades diárias, no exercício da assistência direta aos pacientes, no contato com visitantes e outros profissionais da equipe de saúde, no manuseio de materiais e equipamentos, no ambiente de trabalho. 
A problemática requer particular atenção por parte dos administradores, de toda a equipe de saúde e do próprio trabalhador, já que se busca estabelecer estratégias de prevenção e promoção à saúde dos profissionais de enfermagem, a partir da revisão dos processos de trabalho (CARDO; BELL, 1997; BRASIL, 1999).

\section{Caracterização dos ATMB segundo a função exercida}

Tabela 2 - Distribuição anual das notificações dos ATMB na equipe de enfermagem do HURNP e CR*respectivos, segundo a função do acidentado. Londrina, 1995 a 2000.

\begin{tabular}{l|r|r|r}
\hline \multirow{2}{*}{ FUNÇÃO } & \multicolumn{3}{|c}{ TOTAL } \\
\cline { 2 - 4 } & $\mathrm{n}$ & $\%$ & $\begin{array}{c}* \mathrm{C} \mathrm{R} \\
\text { MÉDIO } \\
\text { ANUAL }\end{array}$ \\
\hline AUXILIAR ENFERMAGEM & 203 & 90,2 & 6,8 \\
\hline ENFERMEIRO & 16 & 7,1 & 2,8 \\
\hline ATENDENTE ENFERMAGEM & 6 & 2,7 & 2,5 \\
\hline TOTAL & 225 & 100,0 & 5,9 \\
\hline
\end{tabular}

* Cálculos realizados a partir do número médio anual de trabalhadores da equipe de enfermagem igual a 631,3.

Nos 225 ATMB notificados na equipe de enfermagem, o maior número de casos envolveu os auxiliares em todos os anos. Esses profissionais foram atingidos por 90,2\% (203) do total de ATMB notificados, sendo 70,0\% (21) dos casos em 1996 e 100,0\% em 1997.

Sabidamente, aos auxiliares são atribuídas as tarefas de higienização, administração de medicamentos, participação efetiva junto à equipe de saúde para prestar assistência a pacientes que se encontram em situações de urgência ou emergência; também lhes são confiados o manuseio e o preparo de instrumentos cirúrgicos após a utilização, o manuseio de excreções e fômites contaminados. Trata-se, portanto, de circunstâncias que predispõem a maiores riscos de ATMB.

A maior exposição dos auxiliares de enfermagem aos ATMB consta em vários estudos que abordam este tema entre os trabalhadores da equipe; entre eles estão Machado et al. (1992) com total de 52,80\% (19) dos casos, Gir, Costa e Silva, (1998) com 42,50\% (34), Prado et al. (1999) com 43,00\% (10).

Outros autores, realizando estudos que contemplavam todos os profissionais de saúde, também encontraram valores expressivos destes acidentes atingindo os trabalhadores da referida categoria profissional. Entre eles estão Kuchenbecker (1999) com 20,00\% do total, Caetano, Loja e Lima, (2000) com 34,00\% (108), Chaves (2000) com 32,95, com $57,20 \%$.

Esse cenário aponta para a necessidade de estudos específicos acerca da atuação dessa categoria profissional. Esse grupo representa o maior número de trabalhadores da equipe de enfermagem, cuja realidade dos processos de trabalho e de vida, possivelmente, exercem interferência no seu desgaste. E, sabidamente, os AT fazem parte deste contexto.

Os enfermeiros, por sua vez, foram acometidos por 7,1\% (16) dos acidentes desta natureza. Contudo, chamaram a atenção os anos de 1995 e 1997, pela ausência de notificações por parte destes profissionais de enfermagem. Ainda, o maior número das ocorrências deu-se no ano de 1996, respondendo por $23,3 \%$ (7) dos casos notificados naquele período.

Já os atendentes de enfermagem foram responsáveis por 2,7\% (6) de tais acidentes. Nos anos de 1997 e 1998 não ocorreram notificações neste grupo profissional, enquanto o maior número de casos deu-se em 1995, com 9,5\% (2) do total.

Relativamente aos $\mathrm{CR}$ verificados, ressalta-se que os auxiliares de enfermagem mostraram coeficiente anual com valores praticamente crescentes de 1995 a 1998, e declínio em 1999 e novo aumento em 2000. O CR médio anual total foi de 6,8 acidentes para cada 100 trabalhadores da mesma categoria, estando estes valores entre 4,2 em 1997 e 10,7 em 1998. Apresentaram os maiores os maiores valores do indicador para ATMB em todos os anos, com exceção do ano de 1996, quando foram superados pelos enfermeiros. 
Quanto aos enfermeiros, avaliando-se os respectivos CR dos ATMB, ano a ano, foi possível constatar que estes apresentaram valor médio anual de 2,8 acidentes para cada 100 trabalhadores. O maior valor foi em 1996, quando o CR igual a 7,6 acidentes para cada 100 profissionais da categoria superou o valor numérico das demais.

Uma possibilidade para justificar esses resultados diz respeito ao fato de que, ele, pela sua maior capacitação, estariam mais preparados para a prevenção dos acidentes, e, conseqüentemente, apresentariam menor número de ocorrências. Outra hipótese é a de que não tenham realmente ocorrido ATMB com maior frequiência entre os enfermeiros em razão das características diferenciadas das tarefas próprias da profissão; os enfermeiros estariam, portanto, menos expostos aos riscos ocupacionais decorrentes das cargas de trabalho biológicas e mecânicas, características desses acidentes.

Entretanto, foi possível verificar que, nas unidades de trabalho em que estão concentrados os pacientes graves, tais como UTI adulto e pediátrica, Unidade de MI, CC, a exposição dos enfermeiros aos ATMB também ocorreu. Vale dizer que, provavelmente, o diferencial esteja ligado ao tipo de tarefa desenvolvida, e não necessariamente à função.

Os atendentes de enfermagem, por sua vez, apresentaram CR médio anual de 2,5, com ausência de notificações em 1997 e 1998, e maior CR igual a 7,7 no ano 2000.

Possivelmente estes dados evidenciaram os seguintes fatos: as atividades desenvolvidas pelos atendentes não estavam diretamente ligadas ao cuidado dos pacientes, mas isso não foi suficiente para livrá-los dos riscos dos ATMB. Ainda, esses dados revelam que, nas atividades de enfermagem nas instituições hospitalares, o trabalho considerado de menor complexidade não constitui, exatamente, trabalho de menor risco, de menor carga.

As pesquisas que levantaram os CR de ATMB apresentaram-se de particular interesse para o presente trabalho. O quadro 2 sintetiza o resultado dos CR destes estudos e o período compreendido pelo estudo, para facilitar a análise comparativa.

Quadro 2 - Distribuição dos CR de ATMB ou AT com perfurocortantes contaminados em estudos de AT na equipe de enfermagem, por categoria profissional.

\begin{tabular}{l|c|c|c|c}
\hline & \multicolumn{4}{|c}{$* C R$} \\
\cline { 2 - 5 } & $\begin{array}{c}\text { Brandi, } \\
\text { Benatti e } \\
\text { Alexandre } \\
(1998)\end{array}$ & $\begin{array}{l}\text { SARQuIS } \\
(1999)\end{array}$ & $\begin{array}{c}\text { SouZA } \\
(1999)\end{array}$ & $\begin{array}{c}\text { SÊCCO } \\
(2002) * *\end{array}$ \\
\hline TEMPO DE REFERÊNCIA DO INDICADOR & 7 MESES & ANUAL & ANUAL & ANUAL \\
\hline ENFERMEIRO & 4,9 & 2,12 & 3,4 & 2,8 \\
\hline TÉCNICO DE ENFERMAGEM & 1,9 & 0,00 & 1,5 & $\ldots$ \\
\hline AUXILIAR DE ENFERMAGEM & 4,5 & 10,09 & 7,0 & 6,8 \\
\hline ATENDENTE DE ENFERMAGEM & 1,4 & 1,48 & 4,5 & 2,5 \\
\hline TOTAL & 3,8 & 7,60 & 5,7 & 5,9 \\
\hline
\end{tabular}

* CR para cada 100 trabalhadores. ** Dados do presente estudo.

Estes indicadores, como é esperado, sofreram as influências particulares das metodologias utilizadas nos diferentes estudos. Entretanto, eles fornecem dados para uma discussão preliminar e possibilitam avaliações dos diferentes serviços de assistência de enfermagem, cada qual com as especificidades do próprio processo de trabalho.

\section{Caracterização dos ATMB segundo a parte do corpo atingida}

No presente estudo, verificou-se que as mãos dos trabalhadores estiveram envolvidas em 82,7\% (186) dos casos de ATMB notificados, e a maior parte dos acidentes esteve diretamente ligados aos materiais perfurocortantes utilizados no processo de trabalho, com destaque para as agulhas hipodérmicas.

Quanto à distribuição desses 186 acidentes que atingiram as mãos dos profissionais, foi possível observar que os dedos foram afetados em $81,2 \%$ (151) das ocorrências. O risco de acidentes envolvendo essa parte do corpo foi contínuo, em todos os anos, o que já era esperado, uma vez que a enfermagem tem um caráter fortemente manual, que envolve o cuidado direto com os pacientes e a 
manipulação de materiais e equipamentos necessários no desenvolvimento das tarefas. Trata-se, pois, de atividades que predispõem à ocorrência de acidentes envolvendo as mãos.

Analisando-se o CR médio anual igual a 4,9 ATMB com acometimento das mãos para cada 100 trabalhadores, verificou-se que ele apresentou valores bastante superiores aos referentes às demais partes do corpo.

Também os olhos foram atingidos de maneira crescente, ano a ano, pelos acidentes desta natureza, correspondendo ao total de $11,1 \%$ dos ATMB. Esses acidentes decorreram, principalmente, de respingos de sangue durante a técnica de punção venosa ou no manuseio de cateteres venosos e do corte do cordão umbilical no momento do parto. Digno de nota é que $100,0 \%$ (25) dos acidentes envolvendo os olhos ocorreram com os auxiliares de enfermagem, o que confirma a maior participação destes profissionais nas tarefas de maior risco.

Muitos autores também encontraram altas freqüências de AT entre pessoal de enfermagem com acometimento das mãos, entre os quais Monteiro, Carnio e Alexandre (1987), Santos et al. (1989), Machado et al. (1992), Brandi, Benatti e Alexandre (1998), Caetano, Loja e Lima (2000), Pungpapong et al. (1999), Marchese et al. (2000), Sêcco e Gutierrez (2001a, 2001b).

Estudos mais pormenorizados dos processos de trabalho que envolvem as atividades da assistência de enfermagem devem ser realizados com vistas à prevenção desses acidentes, em especial daqueles que dizem respeito às mãos dos profissionais de enfermagem.

Esses achados, que evidenciaram expressivo número de ATMB com acometimento das mãos dos profissionais de enfermagem, corroboram o caráter fortemente manual da profissão decorrente do compromisso com o cuidar em enfermagem.

\section{Caracterização dos ATMB segundo a natureza da lesão}

A Tabela 3 mostra a distribuição dos ATMB segundo a natureza da lesão, ano a ano, com os respectivos CR.

Tabela 3 - Distribuição anual das notificações dos ATMB na equipe de enfermagem do HURNP, segundo a natureza da lesão. Londrina, 1995 a 2000.

\begin{tabular}{l|r|r|r}
\hline \multirow{2}{*}{ NATUREZA DA LESÃo } & \multicolumn{3}{|c}{ TOTAL } \\
\cline { 2 - 4 } & $\mathrm{N}$ & \multicolumn{1}{|c}{$\%$} & $\begin{array}{c}\text { * C R } \\
\text { MÉDIO } \\
\text { ANUAL }\end{array}$ \\
\hline PERFURAÇÃO & 159 & 70,7 & 4,2 \\
\hline CORTE & 21 & 9,3 & 0,6 \\
\hline OUtROS & 45 & 20,0 & 1,2 \\
\hline TOTAL & 225 & 100,0 & 5,9 \\
\hline
\end{tabular}

* Cálculos realizados a partir do número médio anual de trabalhadores da equipe de enfermagem igual a 631,3.

Os dados da Tabela 3 demonstraram que 70,7\% (159) dos ATMB apresentaram lesões por perfuração nos trabalhadores envolvidos. As lesões por corte atingiram o pessoal de enfermagem em 9,3\% (21) dos casos, e em $8,9 \%$ (20) a ocorrência se deu pelo manuseio de bisturis contaminados.

Foram classificados como outros os demais acidentes notificados. Como exemplo, estão os casos de respingo de sangue ou secreções nos olhos ou outra parte do corpo, respingos de sangue em pele íntegra ou, aqueles em que não havia descrição de qualquer dano ou desconforto físico para o trabalhador. Essas ocorrências representaram 20,0\% (45) dos casos.

Sabidamente, o risco de exposição percutânea ao sangue de pacientes portadores de hepatite B é apresentado em torno de $40,0 \%$ e aos portadores do vírus da AIDS, em torno de 0,3\% (CARDO; BELL, 1997; BRASIL, 1999). Torna-se, portanto, de especial importância considerar estes acidentes, bem como empreender todas as medidas de prevenção possíveis. 
Com respeito à evolução do $\mathrm{CR}$ anual para a referida variável, observou-se que o indicador das perfurações teve o valor médio anual de 4,2 para cada 100 trabalhadores.

Ressalta-se, como já relatado, que há maior dificuldade na prevenção destes acidentes em virtude da maior frequiência com que as atividades que requerem a utilização de agulhas são realizadas, da dinâmica do trabalho envolvido nestes procedimentos, do ritmo imposto pela assistência aos pacientes, das situações de urgência/emergência, das cargas de trabalho envolvidas nos processo do trabalho, da maneira como ele é organizado e desenvolvido pelos profissionais com vistas ao melhor desempenho possível. Algumas descrições das CAT ou NATMB mostram essa realidade:

Estava lavando material do curativo contaminado (material contaminado), quando a pinça perfurou a luva atingindo a região da palma da mão direita.

Estava retirando o material da mesa de instrumentação com luva de procedimentos e técnica correta, quando se acidentou com agulha contaminada.

Funcionária na hora da emergência perfurou o polegar esquerdo com agulha verificando glicemia de polpa digital.

Após puncionar a veia, o paciente se virou esbarrando na auxiliar de enfermagem, que se feriu com a agulha utilizada.

Estava segurando o paciente agitado para a punção e o mesmo, abruptamente, virou o corpo da maca, quando ocorreu o acidente com a agulha contaminada.

Perfurou o dedo durante o atendimento de emergência a paciente grave.

Estas transcrições ilustram a realidade vivida pelos profissionais de enfermagem diante da prática profissional diária.
Muitos autores têm dado a conhecer grande freqüência de ATMB ocorridos por perfurações, corroborando os achados do presente trabalho: Monteiro, Carnio e Alexandre (1987) encontraram 27,06\% (13) dos casos, Machado et al. (1992) 47,20\% (17), Silva (1996) 54,48\% (73), Pungpapong et al. (1999) com 79,00\% (158), Caetano, Loja e Lima (2000) 83,70\%, Belei et al. (2001b) 85,00\% (17), entre outros.

Estes resultados sinalizam a necessidade de realização de novos estudos sobre o assunto no âmbito do Hospital, visando a caracterizar os processos de trabalho e os comportamentos dos trabalhadores diante dos riscos que a atividade proporciona. E, principalmente, apontam para a necessidade de implementação das estratégias de prevenção, dada a grande freqüência com que esses acidentes ocorrem.

No estudo das notificações dos ATMB, segundo a unidade de trabalho da ocorrência, verificou-se que os setores que apresentaram número maior de acidentes desta natureza foram o Pronto Socorro, com o total de $23,1 \%$ (52) do total, a Unidade de Moléstias Infecciosas (MI), com 11,1\% (25), a Unidade de Terapia Intensiva Adulto (UTI) com 10,7\% (24), o Centro Cirúrgico (CC) com 9,8\% (22), a Unidade Masculina (UM) $9,3 \%$ (21). Esses setores, sabidamente, apresentam cargas de trabalho específicas, com intenso volume e dinamismo nas atividades, atendimento ininterrupto nas 24 horas, prestação de assistência aos pacientes graves e com risco de vida.

$\mathrm{Na}$ avaliação dos CR dos ATMB por unidade de trabalho, observa-se que, para esta variável, só foi possível quantificar os CR referentes aos ATMB dos últimos quatro anos, pela indisponibilidade de dados referentes ao número de funcionários, por setor, de 1995 e 1996. 


\section{Caracterização dos ATMB segundo a atividade desempenhada no momento do acidente}

Tabela 4 - Distribuição anual das notificações dos ATMB na equipe de enfermagem do HURNP e CR* respectivos, segundo a atividade desempenhada no momento do acidente. Londrina, 1995 a 2000.

\begin{tabular}{|c|c|c|c|}
\hline \multirow[b]{2}{*}{ ATIVIDADE DESENVOLVIDA } & \multicolumn{3}{|c|}{ TOTAL } \\
\hline & $\mathrm{N}$ & $\%$ & $\begin{array}{l}* \text { C R MÉdIO } \\
\text { ANUAL }\end{array}$ \\
\hline Punção Venosa & 63 & 28,0 & 1,7 \\
\hline $\begin{array}{l}\text { Procedimentos DE } \\
\text { ENFERMAGEM }\end{array}$ & 43 & 19,1 & 1,1 \\
\hline $\begin{array}{l}\text { MANUSEI MATERIAL } \\
\text { CONTAMINADO }\end{array}$ & 37 & 16,4 & 1,0 \\
\hline AdMINISTRAÇÃo MEDICAMENTOS & 34 & 15,1 & 0,9 \\
\hline VENOCLISE RETIRADA & 19 & 8,4 & 0,5 \\
\hline $\begin{array}{l}\text { DESCARTE AgUlHa } \\
\text { CONTAMinADa }\end{array}$ & 16 & 7,1 & 0,4 \\
\hline INSTRUMENTAÇão CirúRGICA & 9 & 4,0 & 0,2 \\
\hline SEM REFERÊNCIA & 4 & 1,8 & 0,1 \\
\hline Total & 225 & 100,0 & 5,9 \\
\hline
\end{tabular}

* Cálculos realizados a partir do número médio anual de trabalhadores da equipe de enfermagem igual a 631,3.

Avaliando-se a atividade desempenhada no momento do acidente, foi possível verificar que as tarefas que oferecem maiores riscos nos anos de 1995 a 2000 foram as punções venosas; isto, tanto para os auxiliares de enfermagem, quanto para os enfermeiros.

As retiradas de venóclise também ofereceram risco elevado, requerendo atenção especial, uma vez que foram responsáveis por 8,4\% (19) dos eventos e conferiram CR médio anual de 0,5 ; essa tarefa é realizada, em grande parte das vezes, pelo auxiliar de enfermagem responsável pela administração de medicamentos. Digno de nota é que esse profissional também é encarregado de realizar as punções venosas nos pacientes, quando necessárias.

Quanto aos ATMB decorrentes da realização do exame de glicemia de polpa digital, ressalta-se que, até 1998, este procedimento era majoritariamente executado pelos alunos de Medicina atuantes no
Internato. Após esta data, por decisão administrativa, a atividade passou para a equipe de enfermagem, e mais especificamente, para os auxiliares. Analisandose as datas das notificações dos ATMB ocorridos durante a realização do referido exame, observouse que, dos 13 acidentes, 92,3\% (12) deram-se após a inclusão desta tarefa aos profissionais de enfermagem. Portanto, a alteração no processo de trabalho, como era esperado, aumentou o risco dos acidentes desta natureza.

Da mesma forma, o manuseio de materiais cirúrgicos e instrumentos contaminados, tarefa específica dos auxiliares e atendentes de enfermagem, revela uma importante atividade de risco para todo o pessoal que desenvolve esta atividade. Essa tarefa consiste em reorganizar o ambiente de trabalho, e em fazer o primeiro processamento de materiais contaminados que devem ser encaminhados ao Centro de Material para esterilização.

$\mathrm{O}$ risco de ATMB proveniente desta atividade desenvolvida pela equipe de enfermagem requer, além da observação das normas de biossegurança pelo próprio trabalhador, a obediência a essas mesmas normas por parte dos demais profissionais envolvidos na dinâmica da assistência à saúde. Sendo assim, torna-se tarefa ainda mais complexa, principalmente em se tratando de um hospital-escola, com alta rotatividade de profissionais, com dificuldades para manter uniformidade na obediência a normas e rotinas.

Este estudo chamou a atenção para o fato de que em 8,9\% (20) dos casos de ATMB houve a participação de outra pessoa da equipe de saúde na ocorrência do acidente. Em 5,3\% (12) dos casos houve exposição a agulhas contaminadas, em $0,4 \%$ (1) caso o instrumental cirúrgico estava contaminado e, em 3,1\% (7) das ocorrências, houve a presença de lâminas de bisturi contaminadas colocadas em locais impróprios.

Esses dados mostram que esses acidentes, embora freqüentes e muitas vezes desconsiderados 
quanto à sua gravidade, fazem parte do dia-a-dia do processo de trabalho, e são considerados pelo pessoal como "mal necessário", inerente à sua condição profissional, à sua classe social, ao seu trabalho, à sua vida, enfim.

Outro fato que chama a atenção é que em apenas 1,4\% (6) acidentes, houve informação sobre o acidente que ocorreu por ocasião de recapagem de agulha durante as tarefas de administração de medicamentos. Pode-se aventar a hipótese de que este comportamento esteja diminuído entre os componentes da equipe. Estes dados contrapõemse aos de Rowe e Giuffre (1991), Prado et al. (1999), Caetano, Loja e Lima, (2000) e Chaves et al. (2000), que encontraram entre as situações de maior risco o reencape de agulhas.

Muitos autores têm estudado ATMB entre profissionais de saúde, e, mais especificamente, profissionais de enfermagem, sob a ótica da atividade desempenhada no momento do acidente: Rowe e Giuffre (1991), Mccormick et al. (1991), Souza (1999), Prado et al. (1999), Brandi, Benatti e Alexandre (1998), Gir, Costa e Silva, (1998).

Em síntese, esses dados possibilitam o levantamento das atividades de maior risco para as equipes de enfermagem, segundo as especificidades dos processos de trabalho de cada Instituição Hospitalar e de cada unidade específica de trabalho. O conhecimento dos riscos, participantes das cargas de trabalho embutidas em cada tarefa e no conjunto maior da atividade profissional, possibilita o estabelecimento de estratégias de prevenção próprias para cada realidade.

\section{Considerações Finais}

Verificou-se que, dos 421 acidentes notificados, $53,4 \%$ (225) referiram-se a ATMB, com Coeficiente de Risco (CR) médio anual de 5,9 acidentes para cada 100 trabalhadores. Os auxiliares de enfermagem foram acometidos por 90,2\% (203) dos ATMB notificados apresentando o maior CR médio anual, igual a 6,8 . A parte do corpo mais atingida foram as mãos, apresentando freqüência de $82,8 \%$ dos casos e CR médio anual de 4,9. As perfurações representaram o total de 70,7\% (159) dos ATMB e mostraram CR médio anual de 4,2, associadas, principalmente, às tarefas de punções venosas. Em $11,6 \%$ (26) dos ATMB houve exposição ocupacional a pacientes soropositivos para HIV.

A pesquisa aponta para a necessidade de manutenção de medidas educativas para os profissionais de enfermagem da Instituição, na intenção de promover maior capacitação profissional, bem como da necessidade da revisão dos processos de trabalho com a participação de todos os envolvidos, trabalhadores e administradores, em razão dos riscos e cargas apresentados. Também foi apontada a necessidade da prevenção de doenças ocupacionais graves como a AIDS e as Hepatites B e $\mathrm{C}$ a que os profissionais estão expostos.

Aponta, ainda, para a importância da orientação da equipe quanto aos procedimentos legais de notificação dos AT e da sistematização de ações de vigilância epidemiológica, objetivando a informação para a ação.

A busca de novas tecnologias na área de Saúde do Trabalhador, bem como a sua efetiva implantação, é responsabilidades de todos os envolvidos no mundo do trabalho, uma vez que ele é condição indispensável para a promoção humana.

\section{Referências}

BARBOSA, A. Riscos ocupacionais em hospitais: um desafio aos profissionais da área de saúde ocupacional. 1989. 126f. Dissertação (Mestrado em Ciências da Enfermagem) - Faculdade de Enfermagem, Universidade Federal de Santa Catarina, Florianópolis, 1989.

BELEI, R. A.; CARRILHO, C. M. D. M.; PAIVA, N. S.; GUASSI, D. N.; OLIVEIRA, F.; GUARIENTE, M. H. D. M. O impacto do acidente com material biológico na vida de profissionais e alunos em um hospital universitário. Espaço para a Saúde, Brasília, v.2, n.2, jun.2001. Disponível em: <http://www.ccs.br/espacoparasaude/v2n2/doc/ acidente.htm>. Acesso em: 20 ago. 2001. 
BRANDI, S.; BENATTI, M. C.; ALEXANDRE, N. M. C. Ocorrências de acidentes de trabalho por material perfurocortante entre trabalhadores de enfermagem de um Hospital Universitário da cidade de Campinas, Estado de São Paulo. Revista da Escola de Enfermagem, São Paulo, v.32, n.2, p.124-133, ago. 1998.

BRASIL. Decreto nº. 611, de 21 de julho de 1992. Dá nova redação ao regulamento dos Benefícios da Previdência Social. Lex: coletânea de legislação e jurisprudência, São Paulo, v.56, p.488, jul./set. 1992a.

BRASIL. Lei no ${ }^{\circ}$ 8.213, de 24 de julho de 1991. Dispões sobre o Plano de Benefícios da Previdência Social e dá outras providências. Lex: coletânea de legislação e jurisprudência, São Paulo, v.55, p.461-493, jul./set. 1992b.

BRASIL. Ministério da Saúde. Coordenação Nacional de DST e AIDS. Manual de Condutas: exposição ocupacional a material biológico: hepatite e HIV. Brasília, 1999. 20p.

BRASIL. Ministério da Saúde. GESTHOS Gestão Hospitalar: Capacitação à distância em Administração Hospitalar para Pequenos e Médios estabelecimentos de Saúde; Módulo II: Gestão Contemporânea nas Organizações de Saúde/Ministério da Saúde. Brasília: Ministério da Saúde, 2002.

BULHÕES, I. Riscos do trabalho em enfermagem. Rio de Janeiro: Luna, 1994. 221p.

CAETANO, R.; LOJA, T. B.; LIMA, C. X. B. Quando o risco é nosso: acidentes de trabalho com material biológico entre profissionais do HU Pedro Ernesto-UERJ. In: CONGRESSO BRASILEIRO DE SAÚDE COLETIVA, 6., 1999, Salvador. Anais...Salvador: ABRASCO, 2000. v.5, p.493.

CARDO, D. M.; BELL, D. M. Bloodborne pathogen transmission in health care workers, risk and prevention strategies. Infectious Disease Clinics of North America, Philadelphia, v.11, n.2, p.331-346, jun. 1997.

CASTELLANOS, P. L. A epidemiologia e a organização dos sistemas de saúde. In: ROUQUAYROL, M. Z. Epidemiologia \& Saúde. 4. ed. Rio de Janeiro: Medsi, 1999. p.431-459.

CENTERSFORDISEASECONTROLANDPREVENTION. Exposure to Blood What Health-Care Need to Know Department of Health \& Human Services. 1999. Disponível em: < www.cdc.gov/incidocid/hip/BLOOD/exp_to_Blood.pdf >. Acesso em: 20 de fev. 2002.

CENTERSFORDISEASECONTROLANDPREVENTION. Surveillance of Health Care Workers with HIV?AIDS. Disponível em: <http://www.cdc.gov>. Acesso em: 20 abr. 2001.

CHAVES, S. M. C. et al. Cuidado e prevenção integrados: acidentes de trabalho em um hospital geral. In:
CONGRESSO BRASILEIRO DE SAÚDE COLETIVA, 6. 2000, Salvador. Anais...Salvador: ABRASCO, 2000. v.5, p.485.

GIR, E.; COSTA, F. P. P.; SILVA, A. M. A enfermagem frente a acidentes de trabalho com material potencialmente contaminado na era do HIV. Revista da Escola de Enfermagem, São Paulo, v.32, n.3, p.262-272, out.1998.

HOEFEL, H. H. K.; SCHNEIRDER, L. O. O profissional da saúde na cadeia epidemiologica. In: RODRIGUES, E. A. C.; MENDONÇA, J. S.; AMARANTE, J. M. B. Infecções hospitalares: prevenção e controle. Rio de Janeiro: Savier, 1997. p.352-367.

KUCHENBECKER, R. Exposição ocupacional a sangue e secreções corporais no Sistema Único de Saúde em Porto Alegre: epidemiologia e políticas de prevenção. 1999. 164f. Dissertação (Mestrado em Epidemiologia) Departamento de Medicina Social, Universidade Federal de Pelotas. Pelotas, 1999.

LAURENTI, R. et al. Estatísticas de Saúde. 2. ed. São Paulo: EPU, 1987.

MACHADO, A. A.; COSTA, J. C.; GIR, E; MORIYA, T. M.; FIGUEIREDO, F. C. Risco de infecção pelo virus da imunodeficiência adquirida humana (HIV) em profissionais de saúde. Revista da Saúde Pública, São Paulo, v.26, n.1, p.54-56, fev.1992.

MARCHESE, L. T.; EL SAYED, S., MARQUES, A. P., BASSO, M. R.; MARTINS, F. P., PASSOS, A. H. R., COSTA, D. R. Acidentes inadvertidos en equipos quirúrgicos. Revista de Cirugía Infantil, Buenos Aires, v.10, n.3, p.129-135, 2000.

McCORMICK, R. D. et al. Epidemiology of hospital sharps injuries a 14 years pospective study in the pré-AIDS and AIDS eras. American Journal Medicine, New York, v.91, suppl. 3B, p.301S-307S, 1991.

MENDES, R. Aspectos conceituais da patologia do trabalho. In: Patologia do trabalho. Rio de Janeiro: Atheneu, 1995. p.34-47.

MONTEIRO, M. S.; CARNIO, A. M.; ALEXANDRE, N. M. C. Acidentes de trabalho entre o pessoal de enfermagem de um hospital universitário. Revista Brasileira de Enfermagem, Brasília, v.40, n.2/3, p.89-92, 1987.

OLIVEIRA, M. G.; MAKARON, P. E.; MORRONE, L. C. Aspectos epidemiológicos dos acidentes de trabalho em um hospital geral. Revista Brasileira de Saúde Ocupacional, Brasília, v.10, n.40, p.26-30, 1982.

PARANÁ. Secretaria de Saúde. Coordenação Estadual de DST/AIDS. Manual de informações sobre acidente profissional com material biológico. [Curitiba]:Secretaria de Saúde, 1998. 25p. 
PRADO, M. A. et al. A equipe de saúde frente aos acidentes com material biológico. Nursing, São Paulo, v.2, n.19, p.22-24, dez. 1999.

PUNGPAPONG, S. et al. The risk of occupational HIV exposure among Thai Helathcare Workers. Southeast Asian Journal of Tropical Medicine and Public Health, Bangkok, v.30, n.3, p.496-503, set. 1999.

RODRIGUES, A. B.; MAGALHÃES, M. B. B.; SALES, S. M. M. A questão do vírus da imunodeficiência humana e auto proteção no trabalho. Revista Brasileira de Enfermagem, Brasília, v.48, n.3, p.272-285, jul./set. 1995.

ROWE, M. P.; GIUFFRE M. Evaluating needlestick injuries in nursing personnel. American Association Occupational and Health Nurses Journal, Thorofore, v.39, n.11, p.5037, nov. 1991.

SANTOS, W. D. F.; CARMO, E. J.; OLIVEIRA, M. Z.; ABROCESI, S.; MARTINS, A. S. P.; FERREIRA, E. T. R. Acidentes típicos de trabalho em pessoal de enfermagem: fatores associados. Revista Brasileira de Saúde Ocupacional, São Paulo, v.17, n.68, p.38-42, out./dez.1989.

SARQUIS, L. M. M. Acidentes de trabalho com instrumentos perfurocortantes: ocorrências entre os trabalhadores de enfermagem. 1999. 138f. Dissertação (Mestrado em Administração dos Serviços de Enfermagem) - Escola de Enfermagem, Universidade de São Paulo. São Paulo, 1999.

SÊCCO, I. A. O. Acidentes de Trabalho com Material Biológico na Equipe de Enfermagem de Hospital Escola Público de Londrina - PR. 2002. 237f. Dissertação (Mestrado em Saúde Coletiva) - Universidade Estadual de Londrina. Londrina: 2002.
SÊCCO, I. A. O.; GUTIERREZ, P. R. Notificações de acidentes de trabalho em Universidade Estadual do Paraná, de 1995 a 2000: uma contribuição à saúde do trabalhador. In: CONGRESSO BRASILEIRO DE ENFERMAGEM, 53., 2001, Curitiba. Anais...Curitiba: Associação Brasileira de Enfermagem, 2001a. CD-Rom.

SÊCCO, I. A. O.; GUTIERREZ, P. R. Acidentes de trabalho e riscos ocupacionais em Hospital Escola Público: estudo das notificações. In: CONGRESSO BRASILEIRO DE ENFERMAGEM, 53., 2001, Curitiba. Anais...Curitiba: Associação Brasileira de Enfermagem, 2001b. CD-Rom.

SILVA, V. E. F. Estudo sobre acidentes de trabalho ocorridos com trabalhadores de enfermagem de um hospital de ensino. 1988. 203f. Dissertação (Mestrado em Enfermagem) - Escola de Enfermagem, Universidade de São Paulo. São Paulo, 1988.

SILVA, V. E. F. O desgaste do trabalhador de enfermagem: estudo da relação trabalho de enfermagem e saúde do trabalhador. 1996. 289f. Tese (Doutorado em Enfermagem) - Escola de Enfermagem, Universidade de São Paulo. São Paulo, 1996.

SOUZA, M. Acidentes ocupacionais e situações de risco para a equipe de enfermagem: um estudo em cinco hospitais do município de São Paulo. 1999. 163f. Tese (Doutorado em Enfermagem) - Escola de Medicina, Universidade Federal de São Paulo. São Paulo, 1999.

UNIVERSIDADE ESTADUAL DE LONDRINA. Relatório de Gestão dos Órgãos Suplementares 1998/1999. Londrina: UEL, 2000.

UNIVERSIDADE ESTADUAL DELONDRINA. Relatório das Funções do Hospital Universitário Regional do Norte do Paraná. Londrina: UEL, 2001. 
